\title{
LA MONOFTALMÍA Y LA CATARATA DE JAMES THURBER
}

\author{
MIR-FULLANA F ${ }^{1}$
}

James Thurber fue posiblemente el escritor, diseñador y humorista americano (1) de mayor influencia en el siglo XX. Nació el 8 de diciembre de 1894 en Columbus (Ohio) y era el segundo de tres hermanos. Heredó de su madre el humor y una extraordinaria memoria que tanto le serviría a lo largo de su vida, especialmente cuando sus problemas visuales se agravaron.

James perdió un ojo en la infancia de forma traumática. El accidente ocurrió un día del verano de 1901 a sus siete años cuando jugaba con su hermano William a Guillermo Tell. Una flecha de madera impactó en su ojo izquierdo ocasionando un estallido del globo ocular. Lo llevaron a un médico de cabecera que aconsejó no tocar el ojo y únicamente lo ocluyó con un vendaje. Un mes más tarde fue intervenido quirúrgicamente por un especialista enucleándole el ojo traumatizado y colocándole una prótesis de cristal como se hacía en aquella época. El mantener el ojo traumatizado sin tratamiento ocasionó que se desarrollase una oftalmía simpática, inflamación del ojo contralateral originada por una reacción autoinmune contra el ojo lesionado, entidad poco frecuente pero muy peligrosa y temida por los oftalmólogos especialmente en aquella época en la que no se disponía de antimitóticos o fuertes antiinflamatorios para combatirla. Afortunadamente la inflamación mejoró cuando se enucleó el ojo lesionado, un caso sobre diez mil como decía el mismo Thurber, quedándole como secuela una severa disminución visual.

Debido al accidente perdió un año completo de escolarización y cuando regresó a la escuela elemental prestaba tan poca atención que los maestros llegaron a pensar que era sordo pero afortunadamente uno de ellos observó sus cualidades para el dibujo.

Thurber era monoftálmico desde la infancia y además con una baja visión en el ojo restante. A pesar de todo, inició su carrera de dibujante y nove- lista consiguiendo sus primeros éxitos en 1929 (2). El mes de noviembre de aquel año, juntamente con E. B. White, publicó su primer libro que también ilustró, Is Sex Necessary? Or Why You Feel the Way You Do. Tras esta publicación sus dibujos salieron regularmente en el New Yorker (3).

A la edad de treinta y nueve años aumentó su disminución visual al presentar una catarata de la que fue intervenido en 1939 a los cuarenta y cinco años. La intervención, realizada en una época en que la cortisona no se utilizaba, se complicó con una uveítis hipertensiva que obligó a los especialistas a realizar numerosas intervenciones que no consiguieron

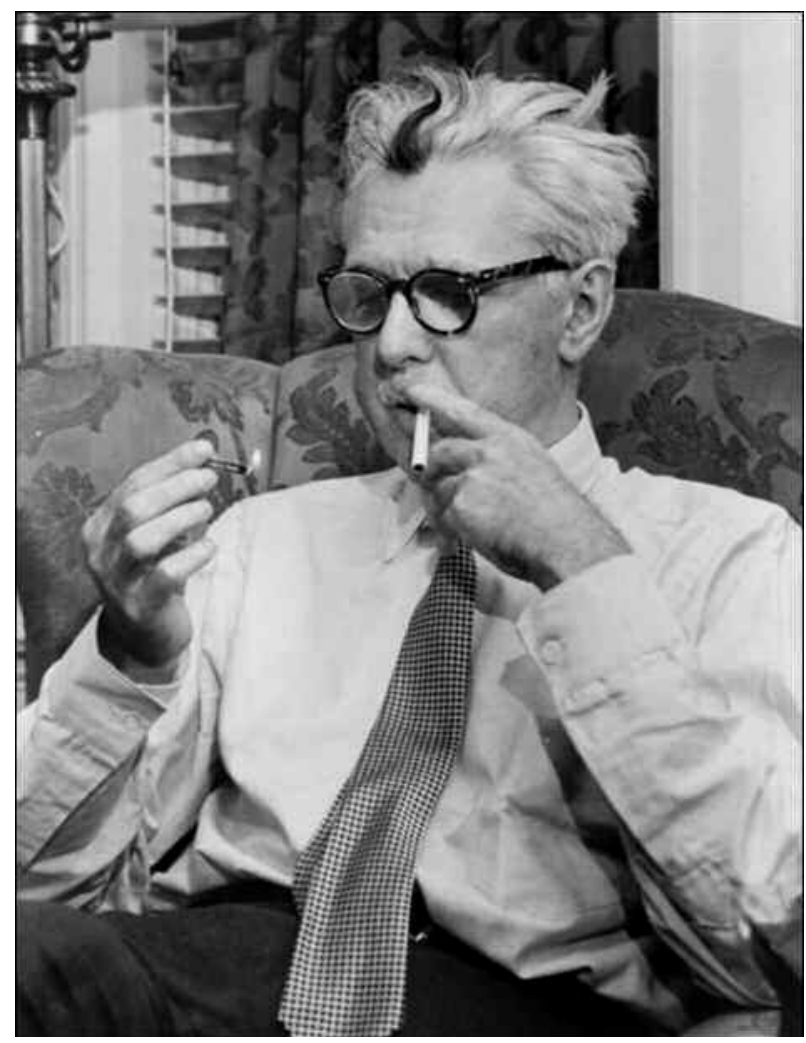

James Thurber.

\footnotetext{
1 Oftalmólogo.

E-mail: Fmir@mutuabalear.es
} 


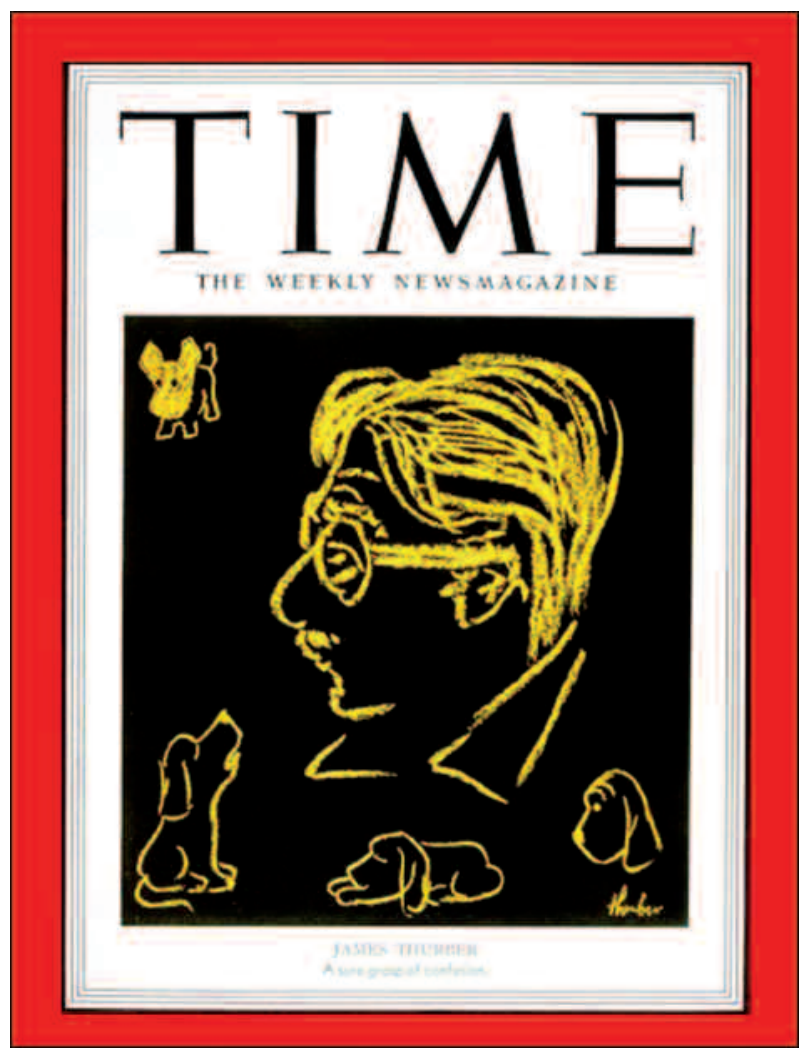

Portada de The Time con autorretrato de Thurber.

recuperar agudeza visual. La segunda intervención fue realizada el 22 de octubre de 1940 sin éxito y así hasta un total de cinco, todas fallidas.

A partir de 1942, la visión de Thurber era tan deficiente que para poder continuar dibujando se vio obligado a utilizar un magnificador adosado a la cabeza como los joyeros, una lupa Zeiss que como él mismo decía, le hacía parecer un marciano (4).

Es realmente admirable el espíritu de superación de Thurber ya que con una mínima visión continuó escribiendo con un grueso lápiz a razón de veinte palabras por página y dibujando con gran dificultad ayudándose de una estilográfica fluorescente y de un negatoscopio para aumentar el contraste, realizando dibujos blancos sobre fondo negro, aparte de los sistemas ópticos magnificadores citados.

La salud de Thurber se deterioraba y en 1944 sufrió una neumonía y una apendicitis necrosada con peritonitis que casi lo lleva a la tumba. En 1947, la disminución de la poca vista que le quedaba, le obligó a entregar al The New Yorker los últimos trescientos siete dibujos cómicos que conservaba. A pesar de su quebrantada salud, recibió homenajes y títulos
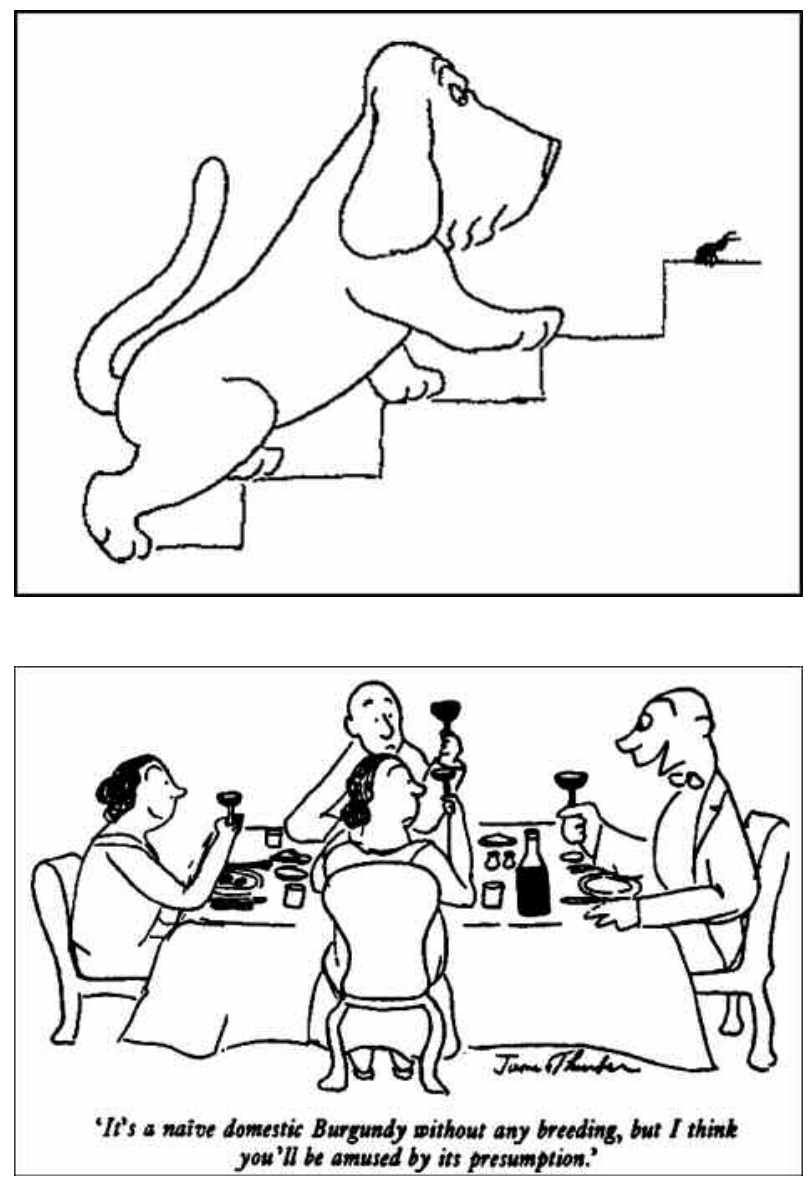

durante la década de 1950, pero el que le hizo mayor ilusión fue la invitación en 1958 para incluirlo en el cuadro de honor de la revista inglesa de humor más importante, la revista Punch: era el primer americano desde Mark Twain en recibir este honor.

A partir de 1957, la visión de Thurber se redujo a proyección luminosa, pero siempre se negó a aprender el sistema Braille y continuó escribiendo hasta el final ya que su extraordinaria memoria le otorgaba el privilegio de poder dictar obras enteras a su secretaria o a su mujer Helen.

El 3 de octubre de 1961 cuando volvía de escuchar más que ver una obra en Broadway, sufrió una lipotimia. Al llegar a su domicilio perdió de nuevo el conocimiento. En el hospital le diagnosticaron un tumor cerebral del que fue operado pero no se recuperó del coma postoperatorio muriendo el 2 de noviembre de aquel mismo año.

Thurber nunca se consideró un artista, pero su maestría innata por la línea ha sido comparada con la de Matisse. Sus dibujos se caracterizan por las líneas curvas, ondulantes, suaves y con pocos deta- 
lles, incluso en las representaciones de personas, estilo que se ha relacionado con su baja visión (5).

\section{BIBLIOGRAFÍA}

1. Bernstein B. Thurber. A Biography. New York: Arbor House, 1975.
2. Thurber H, Weeks E. Selected Letters of James Thurber. New York: Penguin, 1981.

3. Ninney H. James Thurber: His Life and Times. New York: Henry Holit \& Co, 1995.

4. Grauer NA. Remember Laughter: A Life of James Thurber. Lincoln: University of Nebraska Press, 1994.

5. Lanthony P. La vision des peintres. Lausanne: L'Age de l'homme, 1999. 